\title{
Nuevas tecnologías y proceso jurisdiccional en el ámbito iberoamericano. Prueba, medidas cautelares y comunicaciones procesales*
}

Manuel Ortells Ramos

\section{Introducción}

Bajo la denominación de nuevas tecnologías caben avances científicos y tecnológicos muy diversos y que afectan a diferentes aspectos de la vida humana y de las relaciones sociales. No obstante, las tecnologías que pueden proyectarse sobre el proceso y, particularmente, sobre las tres materias referidas en el subtítulo de la ponencia — prueba, medidas cautelares y actos de comunicación - lo son, sin duda, las que se ha dado en llamar tecnologías de la sociedad de la información. Es decir, las tecnologías de archivo, tratamiento y transmisión de imágenes, sonidos y datos entre los equipos técnicos adecuados; las nuevas tecnologías ligadas a la electrónica, la informática, las telecomunicaciones y sus aplicaciones.

\section{Referencia a la biotecnología}

No obstante, conviene referirse, brevemente, a la incidencia en el proceso de las tecnologías desarrolladas en los campos de la biología y la genética. Esa incidencia tiene una doble manifestación:

"Texto-base de la exposición de la ponencia para Iberoamérica presentada en las «Jornadas del Instituto Iberoamericano de Derecho Procesal», celebradas en Montevideo del 16 al 18 de octubre de 2002. Para el correspondiente aparato crítico hay que remitir a la edición de la ponencia integra: M. Ortells Ramos, «Incidencia de las nuevas tecnologías en el proceso jurisdiccionab. Especial análisis de las cuestiones referentes a la prueba, a las medidas cautelares y a las comunicaciones procesales, en: XVIII Jornadas Iberoamericanas y XI Jornadas Uruguayas de Derecho Procesal, Editorial Fundación de Cultura Universitaria, Montevideo-Uruguay, 2002, pp. 607-675. 
10) Ha generado el descubrimiento de nuevas fuentes de prueba, que podrán ser introducidas en el proceso generalmente mediante la prueba pericial.

Es el caso de las pruebas biológicas que permiten establecer o excluir directamente la paternidad, pero también la maternidad si su atribución resulta afectada por conductas de alteración de la identidad de la madre o del hijo. Los avances científico-técnicos han determinado que las posibilidades materiales de investigación biológica con resultados fiables hayan progresado desde las pruebas heredo-biológicas a las actualmente muy difundidas pruebas hematológicas, continuando la tendencia evolutiva hacia los análisis de $\mathrm{ADN}$, que permiten alcanzar resultados de gran seguridad.

Los análisis de ADN con fines de identificación en la investigación penal, son otra aplicación del avance científico-técnico antes mencionado. La efectividad de esta técnica de investigación requiere regular la recogida de muestras biológicas y la obtención de las mismas en el cuerpo de la persona sospechosa, el análisis de las muestras y la formación y tratamiento de ficheros de los datos obtenidos.

$2^{\circ}$ ) Las nuevas tecnologías biológicas y genéticas hacen posible la aparición de nuevas realidades sociales, que están necesitadas de regulación jurídica y que pueden dar lugar a nuevas situaciones litigiosas.

Las técnicas de reproducción humana asistida, cuyo reconocimiento legal modifica los supuestos de hecho constitutivos de la relación paterno-materno-filial, influyen, de diverso modo, en la tutela judicial referida a la declaración o impugnación de esa relación.

En segundo lugar, dado que resulta fácticamente posible la investigación y experimentación con material genético humano, se plantea la cuestión de su régimen legal y los problemas de actuación jurisdiccional de esa ordenación.

\section{El significado relativo de las novedades tecnológicas}

El examen de la incidencia de las nuevas tecnologías en el proceso conduce a un planteamiento relativista en varios sentidos.

A) Nuevas tecnologías y grado de desarrollo social y económico:

El progreso social y económico de un país condiciona el grado de implantación y uso social de las nuevas tecnologías informáticas y de la telecomunicación. 
Pero, dentro de esta observación, hay que matizar que:

10) La implantación y el uso social de las tecnologías informática y de la comunicación se caracteriza por concentrarse, incluso dentro de un mismo país, en segmentos sociales determinados y en las áreas geográficas habitadas por aquellos. Fuera de esos ámbitos sociales y territoriales existe un elevado número de "desconectados" o "desenganchados"

Estos datos fundamentan una importante reflexión crítica acerca de la procedencia de generalizar el uso de las nuevas tecnologías como instrumentos para realizar la actividad procesal. Según cómo se regule ese uso podría infringirse o ponerse en peligro el principio de igualdad en el acceso a la jurisdicción y en la asunción de las posibilidades y cargas establecidas por la ley procesal.

$\left.2^{\circ}\right)$ La incidencia de las nuevas tecnologías en el proceso también está condicionada por las prioridades políticas que se establezcan para la asignación del gasto público.

En definitiva, la dotación a la jurisdicción de los medios humanos (personal técnico, gastos de formación específica del personal jurisdiccional y auxiliar) y de los medios materiales necesarios para la aplicación de las nuevas tecnologías al proceso, es un componente más del problema de los recursos presupuestarios destinados a la justicia. Y no es extraño que entre las prioridades de modernización tecnológica de los poderes públicos, el Poder Judicial no haya ocupado los primeros puestos, en los que, generalmente, está instalada la administración dirigida por el Poder Ejecutivo, y, especialmente, la competente en materia tributaria o fiscal.

B) Nuevas tecnologías y pervivencia de problemas respecto de tecnologías que ya no son nuevas:

En el momento presente no sería, en verdad, acertado calificar como nuevas tecnologías la fotografía, la cinematografía, las grabaciones magnetofónicas y videomagnéticas, el telex, el telefax o telecopia, el telegrama y la telefonía. A pesar de que, en el contexto histórico de nuestra civilización, el descubrimiento de esas técnicas es relativamente próximo en el tiempo, la aceleración del progreso tecnológico en los últimos años ha sido tal, que las mismas han quedado rápidamente desposeídas del sello de la novedad.

Sin embargo, estas técnicas de ya muy frecuente uso en los países de nuestro ámbito, ofrecen una oportunidad de reflexión sobre la relatividad de la novedad tecnológica y el proceso. Hay, en efecto, ordenamientos que todavía hoy se resisten a la recepción de estos medios técnicos como 
forma de los actos de comunicación entre tribunal, partes y terceros. Y en otros sigue abierta la cuestión de su recepción como medios de prueba.

\section{Las diversas formas de incidencia de las tecnologías informáticas $\mathrm{y}$ de las telecomunicaciones en el proceso jurisdiccional}

En términos generales puede decirse que la incidencia se produce de dos formas:

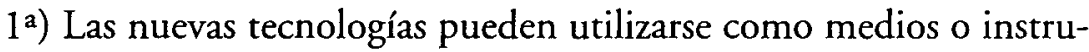
mentos para la realización de la actividad procesal, tanto del tribunal y de sus auxiliares, como de las partes.

Los grados posibles de utilización de las nuevas tecnologías como instrumento de la actividad procesal son muy diversos. Abarcan desde su empleo como instrumento de trabajo para la elaboración material en la forma tradicional de los actos legalmente previstos (por ejemplo redacción de actos escritos mediante una aplicación informática de tratamiento de texto), hasta la creación de una nueva forma del procedimiento -distinta de la oralidad y de la escritura-, pasando por su uso en los actos de comunicación procesales, uno de los aspectos que debe ser objeto de especial consideración.

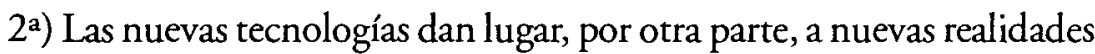
sociales, consiguientemente, también, a nuevas realidades jurídicas, y, por tanto, a nuevas materias litigiosas, sobre las que versará la actividad procesal.

En ocasiones la novedad de la materia litigiosa es absoluta — como ocurre, por ejemplo, con la litigiosidad que enfrenta la asignación de nombres de dominio con los derechos de marca y sobre otros signos distintivos-. En otros casos la materia litigiosa es tradicional, pero el uso social de las nuevas tecnologías origina aspectos novedosos en la litigiosidad, por ejemplo, la contratación celebrada en forma electrónica.

$Y$ en este contexto se sitúan los temas de incidencia sobre la prueba y las medidas cautelares.

\section{Las nuevas tecnologías como instrumento del proceso jurisdiccional}

La incidencia más directa de las nuevas tecnologías informáticas y de la comunicación sobre el proceso se produce mediante la utilización de las mismas para la realización de los actos procesales. 
Esta utilización puede presentar grados diversos. Expondré esos grados y sus problemas por orden de intensidad creciente.

1. Utilización de las nuevas tecnologías como instrumento auxiliar para la realización de los actos procesales en las formas tradicionales, escrita u oral.

Este primer grado de aplicación de las nuevas tecnologías ni siquiera altera la forma (escrita u oral) prescrita por la ley para la realización de los actos procesales. Se limita, en unos casos, a la elaboración material de actos escritos. En otros, se aplica a aspectos accesorios o complementarios de la actividad procesal.

Las manifestaciones de esta utilización son, principalmente, de tres clases.

A) Registro de asuntos y seguimiento del estado de tramitación

El uso de las adecuadas aplicaciones informáticas facilita el registro de los asuntos ingresados en los tribunales, con identificación de sus elementos subjetivos y objetivos esenciales, y el seguimiento del estado de tramitación de los asuntos.

La utilización de estas técnicas repercute, en primer lugar, en la mayor precisión y en la más inmediata disponibilidad de tratamientos estadísticos.

Pero también son posibles, en segundo lugar, consecuencias sobre las potestades del juez y las funciones procesales de sus auxiliares. Un adecuado control informático del estado de tramitación de asuntos facilita al secretario judicial la tarea que la ley le encomiende en relación con el impulso de oficio del procedimiento.

Un registro informático suficiente de los elementos subjetivos y objetivos de cada proceso incoado facilita, hasta posibilitarlo realmente, el control de oficio de la litispendencia y de la cosa juzgada si están normativamente establecidos.

B) Elaboración material de actos procesales escritos

La utilización de aplicaciones informáticas de tratamiento de texto y de bases de datos facilita la elaboración material de actos procesales escritos del juez, de sus auxiliares y de las partes. Incluso puede contribuir a la mejora de la calidad técnico-jurídica de esos actos, por la disponibilidad de una completa información legislativa y jurisprudencial. 
Pero, bajo esta utilidad se esconden viejos y nuevos riesgos.

Los intentos antiguos de estandarizar contenidos de actos procesales escritos - documentos impresos con campos a cumplimentar según los elementos del caso concreto- condujeron, en ocasiones, a la corruptela de las resoluciones judiciales que, contra lo dispuesto en la ley, sustituían la motivación por una simple apariencia de la misma, dado que su contenido no versaba sobre los aspectos concretos del caso singular. Ese riesgo subsiste con la elaboración informatizada de actos escritos. En cierto modo, aumenta su sofisticación porque, por ejemplo, con la incorporación de resultados de busca en bases de datos jurisprudenciales una sentencia puede presentar una imagen perfecta de motivación suficiente, aunque escamotee la explicación de los razonamientos que han conducido a la decisión adoptada para el caso concreto.

C) Documentación de los actos procesales orales y medios de grabación y reproducción de la imagen y el sonido

Sin alterar la forma de realización de los actos orales -es decir, manteniendo el requisito de la presencia física de los intervinientes en el acto ante el tribunal - las tecnologías de la imagen y el sonido (grabación magnetofónica, videomagnética y en soporte digital) pueden utilizarse para mejorar la documentación, superando los límites de la documentación escrita.

En todo caso se consigue que la conservación del contenido de las intervenciones orales sea más completa y precisa que la de un acta escrita. Si la técnica aplicada comprende la grabación de imágenes de los intervinientes se logra, incluso, conservar una parte de los elementos que hacen útil la inmediación en la práctica de los medios de prueba personales: los componentes de expresión corporal que, más o menos conscientemente, acompañan a la declaración de la parte o del testigo y que sirven al tribunal para valorar la fiabilidad de la misma.

Obviamente el pleno cumplimiento de la función de esta forma de documentar requiere la intervención del fedatario público judicial, que incorpora a la materialidad de la documentación la especial eficacia jurídica de fehaciencia.

2. Nuevas formas de realización de ciertas clases de actos procesales: Incidencia de las nuevas tecnologías en los actos de comunicación del tribunal con las partes y con terceros, en el auxilio judicial y en 
el auxilio a la justicia y en la presentación por las partes de actos "escritos" al tribunal.

La forma de relación social en la que las nuevas tecnologías han hecho notar más intensamente su influencia ha sido la telecomunicación. Es comprensible que la parte del ordenamiento procesal en la que primero se ha producido la recepción de nuevas tecnologías, o en la que esa recepción se considera más razonable y deseable, es la que rige los actos procesales de comunicación (en sentido amplio) y los actos que, para surtir los efectos que les son propios, precisan de una posterior comunicación o presentación, como los actos de parte (o de algunos terceros) que han de dirigirse al tribunal.

La aplicación de las tecnologías de la comunicación más avanzadas redunda, principalmente, en un acortamiento del tiempo necesario para la comunicación, lo que tiene consecuencias ventajosas sobre el desarrollo del procedimiento: $1^{\circ}$ ) contribuye a la menor duración del procedimiento, pero no menguando el tiempo razonable que el tribunal, sus auxiliares y las partes necesitan para preparar su actividad procesal, sino eliminando los «tiempos muertos» que genera la transmisión de los actos; $2^{\circ}$ ) satisface la urgencia real o implícita en la realización de algunos de estos actos procesales, principalmente los destinados a la solicitud y al otorgamiento de las tutelas cautelar y ejecutiva.

\section{A) Actos de comunicación del tribunal dirigidos a las partes y a terceros}

Aunque actualmente ya no pueden considerarse una tecnología novedosa, el examen de en qué medida los ordenamientos de nuestro ámbito autorizan la práctica de estos actos de comunicación mediante telegrama, telefax, telex o por vía telefónica conduce a concluir que la autorización legal de estas formas está sujeta a diversas restricciones.

Un paso adicional en la incidencia de las nuevas tecnologías en esta materia, consiste en la autorización de los medios telemáticos. Según la información recibida ese paso no se ha dado en los países de América Latina.

En un estadio más avanzado de la recepción de estos nuevos medios se hallan los ordenamientos portugués y español, que cuentan, al menos, con una habilitación legal de principio.

No obstante, la aplicación práctica de esta forma de los actos de comunicación, está subordinada a otros condicionamientos de naturaleza muy diversa. 
Un primer condicionamiento es el de la disponibilidad material de los medios técnicos, que comprende desde la más estricta acepción de disponibilidad (posesión de los medios técnicos con las conexiones necesarias), hasta la adecuada solución de problemas de compatibilidad de sistemas informáticos y de comunicación.

La importancia de este condicionamiento material es diversa según quienes deban ser destinatarios de la comunicación a tenor del correspondiente ordenamiento procesal. Si las comunicaciones han de dirigirse a las partes y éstas deben actuar representadas por profesionales forenses, y más si estos han de integrarse en organizaciones colegiales, resulta más fácil posibilitar materialmente las comunicaciones en esta forma.

Obviamente las dificultades son mayores cuando las comunicaciones han de dirigirse a las partes todavía no personadas en el proceso o a terceros que no deban comparecer con intervención de profesionales forenses.

Solo cabe hacer una excepción a lo último: las comunicaciones dirigidas a empresas y, especialmente, a entidades financieras, dada la ágil adopción por las mismas de las nuevas tecnologías.

Un segundo condicionamiento es la garantía de cumplimiento efectivo de los requisitos de los que legalmente se hace depender la validez y eficacia de los actos de comunicación realizados con medios electrónicos, informáticos y telemáticos.

Normalmente la ley impone específicos requisitos para la validez y eficacia de los actos de comunicación realizados por los medios mencionados: autenticidad —es decir, que el acto provenga del titular del órgano que dice expedirlo- integridad y no alteración del contenido, momentos de expedición y de recepción por el destinatario.

No sería razonable un régimen que obligara a los tribunales a verificar respecto de cada acto concreto de comunicación y según el medio de comunicación utilizado, si cumple los requisitos legales reseñados. La tramitación del proceso resultaría impedida por constantes comprobaciones periciales y testificales referidas, además, a cuestiones de procedimiento.

Las normas muy genéricas de autorización de uso de medios electrónicos, informáticos y telemáticos resultan incompletas desde la perspectiva de una aplicación frecuente y generalizada. Están necesitadas de unas normas complementarias - de rango legal o infralegal- que especifiquen qué clase de medios satisfacen las características técnicas que garantizan el cumplimiento de los requisitos legales. 
Se llega, por este camino, a la necesidad de un régimen jurídico de la seguridad de las comunicaciones electrónicas, que suele concretarse en la regulación de la firma electrónica, en general, y también de los específicos requisitos de su aplicación a los actos de un proceso.

\section{B) Actos de auxilio judicial}

La incidencia de las nuevas tecnologías en el régimen del auxilio judicial es doble.

a) Reducción de los casos en que es necesario utilizar el auxilio judicial

En primer lugar, la utilización de nuevas tecnologías permite reducir los casos en los que es necesario acudir al auxilio judicial.

Esta primera consecuencia tiene dos manifestaciones cuya importancia y grado de novedad son muy diferentes.

Por un lado, en cuanto se autorice la comunicación por envío postal, telegrama, telefax, telex o correo electrónico queda eliminado el paso intermedio del auxilio judicial del tribunal del lugar donde debieran practicarse los actos de comunicación mediante entrega de documentos por un empleado del tribunal.

La segunda manifestación es mucho más novedosa. Las nuevas tecnologías que permiten la transmisión del sonido (comunicación telefónica) y de la imagen y el sonido (videoconferencia) posibilitan evitar el auxilio judicial para la práctica de medios de prueba consistentes en la recepción de declaración a personas, en el reconocimiento de personas o en el reconocimiento de objetos que no puedan ser trasladados ante el tribunal. Es, no obstante, necesaria la actuación del tribunal de la residencia del declarante o de ubicación de la cosa, que deberá realizar las comunicaciones necesarias para preparar la videoconferencia y asegurar la prestación de fe pública judicial en uno de los puntos de la comunicación. Ciertamente estas técnicas también reducen los retrasos que se originan en la prestación del auxilio, pero su principal ventaja es la mejora de la calidad del acto de recepción de la prueba, porque posibilitan conservar, en gran medida, las ventajas que derivan de la inmediación para la mejor apreciación de la prueba.

b) Agilización del requerimiento del auxilio y de la comunicación de su resultado al requirente

Aunque no se alcance una aplicación tan innovadora como la reseñada en el apartado anterior, las nuevas tecnologías - y algunas no tan nuevasinciden en el auxilio judicial acortando los plazos para solicitarlo y los de 
comunicación de sus resultados por parte del tribunal encargado de prestarlo.

La autorización por los ordenamientos de medios de comunicación más ágiles que el envío postal, presenta diversas formas, aunque algunos ordenamientos de nuestro ámbito siguen cerrados a todas ellas.

Un reconocimiento expreso que incluye medios telemáticos lo encontramos en el Derecho costarricense, portugués y en el ordenamiento español, aunque el uso efectivo de estos medios no es frecuente.

Habida cuenta de entre quién se establece la comunicación en caso de auxilio judicial —-conjunto de órganos jurisdiccionales del Estado--, los requisitos de autenticidad, integridad y seguridad pueden alcanzarse mediante el establecimiento de una red corporativa (intranet), cuyos aspectos técnicos y jurídicos pueden ser unitariamente regulados para garantizar el cumplimiento de aquellos.

El carácter definido del círculo de las entidades entre las cuales puede establecerse la comunicación y la estabilidad y continuidad de la misma, posibilita soluciones de seguridad del tipo EDI (Electronic Data Interchange).

Si no se opta por esa alternativa —opción que, por otra parte, no excluye la aplicación complementaria de técnicas de firma electrónicala garantía de la comunicación segura conduce, como en el caso de comunicación a las partes y a terceros, al régimen jurídico de la firma electrónica y su específica aplicación a los actos judiciales.

\section{C) Actos de auxilio a la justicia}

En los ordenamientos de nuestro ámbito, son pocos los que admiten la comunicación por medios distintos a los tradicionales. Telegrama, telefax, teléfono y, por descontado, medios electrónicos son en absoluto desconocidos en Argentina, Chile, Guatemala, y solo con esfuerzos interpretativos podrían entenderse admitidos en México.

En los ordenamientos que autorizan el uso de estas formas, bien sea de modo general, bien sea en casos de urgencia, debe tenerse presente la necesidad de concordar la norma procesal sobre la forma del requerimiento, con las normas que rigen la actividad del órgano público que debe prestar el auxilio.

De hecho, por lo que se refiere a la experiencia española, hubo un frustrante período de coexistencia entre una ordenación procesal que permitía el uso del telex, el telegrama y cualquier otro medio 
(consiguientemente también el telefax) bajo la fe del secretario, para dirigir mandamientos al Registro de la Propiedad, y una legislación registral que desconocía prácticamente - porque no regulaba las específicas necesidades derivadas de su uso- toda forma distinta a la presentación personal de los documentos necesarios en la oficina registral. Actualmente, el Reglamento Hipotecario resuelve el problema, al menos respecto de las resoluciones judiciales remitidas por telefax, que deben causar asiento de presentación sujeto a un plazo de caducidad, dentro del cual ha de presentarse copia fehaciente de la resolución.

Más restringido es el uso, para el auxilio a la justicia, del correo electrónico con firma electrónica.

Algunos ordenamientos — la LEC española de 2000- autorizan el uso de "medios electrónicos, telemáticos, infotelecomunicaciones, o de otra clase semejante", a condición de que esté técnicamente garantizada la autenticidad de la comunicación y de su contenido, la fehaciencia de su remisión y recepción y del momento en que se produjeron.

Ahora bien, la técnica para dar seguridad a las comunicaciones telemáticas es la firma electrónica, cuya efectiva aplicación no solo necesita de una regulación legal, sino también de una estructura de servicios, que debe ser regulada con normas infralegales y debe ser de hecho implantada. En cuanto este necesario segundo escalón para la aplicación de la firma electrónica no alcance a los órganos jurisdiccionales, la comunicación por correo electrónico no podrá ser utilizada. Y ello aunque el régimen jurídico de la actividad de los órganos públicos requeridos, permita que los actos destinados a instar el ejercicio de sus competencias puedan ser realizados mediante una comunicación electrónica segura.

Es decir, renacen los inconvenientes derivados de las discordancias de la norma aplicable al órgano jurisdiccional requirente con la que rige el ejercicio de las competencias del órgano público requerido.

D) Presentación de actos «escritos» de parte por medios electrónicos, informáticos y telemáticos. Realización de actos sujetos a la oralidad mediante videoconferencia.

Debe tratarse, ahora, sobre si los actos procesales de parte que han de dirigirse al tribunal pueden realizarse válida y eficazmente con medios electrónicos, informáticos y telemáticos. Y lo mismo respecto de actos de terceros (peritos, testigos). 
Habría que hacer, de entrada, una distinción entre los actos sujetos a la forma escrita y los que han de realizarse oralmente a presencia del tribunal. Los medios técnicos que podrían - materialmente, sin perjuicio de la necesaria habilitación normativa - utilizarse son diferentes y cada uno plantea problemas propios.

a) Presentación de actos "escritos" en forma posibilitada por nuevas tecnologías

Las técnicas que hacen posible un modo de presentación distinto a la entrega de un escrito firmado en la oficina judicial, han evolucionado desde el telegrama, el telex o el telefax, hasta la comunicación mediante correo electrónico.

La última técnica es expresamente admitida para la presentación de actos procesales de parte en Derecho portugués y en Derecho español.

Los principales problemas que plantea esta forma de remisión - aparte de la disponibilidad material de equipos y de aplicaciones informáticas adecuadas en los puntos de emisión y de recepción - son los relativos a la autenticidad subjetiva del acto - es decir, que procede de quien dice proceder-, a la integridad objetiva del mismo y a la constatación del momento de recepción por el tribunal.

El cumplimiento de estas condiciones remite, nuevamente, al régimen jurídico de la firma electrónica y a su efectiva implantación. Esta firma, en una de sus modalidades de mayor seguridad, es requerida por la norma procesal portuguesa para la validez de los actos procesales en forma electrónica.

b) Realización de actos en forma oral mediante multiconferencia y videoconferencia

Las tecnologías de transmisión del sonido y la imagen posibilitan en sentido fáctico; es decir, sin perjuicio de la necesaria cobertura normativa- que actos que habrían de realizarse con comparecencia personal ante el tribunal, se lleven a cabo por medio de multiconferencia telefónica o de videoconferencia. Esta posibilidad comprendería las intervenciones de las partes (o de quienes postulen por ellas) en juicios orales o en audiencias, y, sobre todo, la práctica de medios de prueba consistentes en una declaración personal (de la parte, de un testigo y también la de un perito, como complemento a la previa presentación de un dictamen escrito).

Tal posibilidad carece de reconocimiento normativo en la mayor parte de los ordenamientos de nuestro ámbito. 
El Derecho portugués limita la aplicación de la técnica de la videoconferencia a la recepción de las pruebas testifical y de declaración de las partes, en supuestos en que sería necesario acudir al auxilio judicial para evitar desplazamientos personales que no se consideran exigibles. A esta causa justificada se añade la de optimizar el aprovechamiento de los servicios prestados por peritos pertenecientes a organismos oficiales, que pueden exponer sus dictámenes por videoconferencia desde su lugar de trabajo.

En Derecho español, la genérica previsión del Art. $230^{\circ} .1$ LOPJ, dio lugar a que, en materia penal y en un caso en que la celebración del juicio estaba condicionada por el factor de la insularidad, se entendiera válida la celebración del mismo por videoconferencia, con el tribunal en su sede y las partes y otros sujetos procesales en lugar distinto. En principio, la Fiscalía General del Estado dictó una instrucción contraria a la validez de la aplicación de la videoconferencia con esa amplitud, pero de modo casi inmediato rectifico ese criterio.

La técnica de la videoconferencia aplicada a la recepción de algunos medios de prueba y, más aun, al conjunto de un acto de juicio oral o audiencia, plantea problemas radicales respecto de las garantías procesales y del sistema de la oralidad.

10) Ha de preverse el desempeño de las funciones de fe pública judicial en el lugar en que no esté constituido el tribunal, para constatar la identidad de los actuantes y las condiciones en las que desarrollan su actuación.

20) La garantía básica de una contradicción efectiva impone que técnicamente se asegure la percepción por las partes o quienes postulan por ellas de todos los acaecimientos relevantes ocurridos en la vista, respecto de los cuales han de tomar postura en sus actos procesales.

$\left.3^{\circ}\right)$ La publicidad general ha de ser respetada, como mínimo, con la accesibilidad por el público, según las reglas generales, al local en el que está constituido el tribunal.

$4^{\circ}$ ) En fin, la inmediación tiene la ventaja de proporcionar marginalmente criterios para la valoración de la declaración, que se deducen del comportamiento del declarante durante la misma. No se pierden con la técnica de la videoconferencia -otra cosa sería la multiconferencia telefónica sin imagen-, pero deben tenerse presentes otros factores, como la incidencia de una tensión personal originada por técnicas de filmación agobiantes para el declarante o la tendencia a cierta relajación de la conciencia del deber de declaración completa y veraz, que suele producirse por la falta de un enfrentamiento directo con el tribunal. 


\section{3. ¿Hacia una nueva forma del procedimiento?}

La previsión legal de la utilización de medios electrónicos, informáticos y telemáticos para la realización de diversas clases de actos procesales singulares permite concebir la posibilidad de que el conjunto del procedimiento, como serie articulada de actos jurídicos mediante los cuales se desarrolla y concluye el proceso, se realice o sustancie en su integridad por aquellos medios.

Sería un proceso civil en el que el tribunal y los abogados intercambiarían los actos escritos y los documentos por e-mail, el tribunal tendría siempre los autos a disposición en su PC, y en el que nadie habría de molestarse en acudir a un señalamiento judicial, sino que intervendría en la audiencia desde la sala de videoconferencia del edificio judicial o desde el despacho.

A) Diversas manifestaciones de procedimientos en línea

Efectivamente, hay manifestaciones de esa forma de procedimiento o de una orientación hacia la misma.

En procesos ante tribunales estatales, la validez — aparte, de la posibilidad material y técnica- de un procedimiento que se desarrollara en la red, es negada en los informes sobre los ordenamientos latinoamericanos.

Aunque el Derecho portugués y el Derecho español autoricen la realización en forma electrónica de actos procesales singulares importantes, esto no permite concluir la validez de un procedimiento judicial realizado, en su conjunto, a través de comunicaciones en la red.

Un procedimiento arbitral en la red se considera, en cambio, viable desde la perspectiva de diversos ordenamientos latinoamericanos. No, sin embargo, en los ordenamientos guatemalteco y portugués.

En Derecho español, salvo problemas que mencionaré al final, la validez de esa forma del procedimiento se ampara en el Art. $21^{\circ}$ de la Ley de Arbitraje, que establece que el procedimiento arbitral se regirá por la voluntad de las partes, por las normas de la institución a la que se haya encomendado la administración del arbitraje y, supletoriamente, por acuerdo de los árbitros. No obstante, el procedimiento arbitral también ha de ajustarse a algunas prescripciones específicas de la ley y, en general, a los principios esenciales de audiencia y contradicción.

Efectivamente, las previsiones más estructuradas de un procedimiento en la red existen respecto de procedimientos arbitrales o de otros medios no jurisdiccionales de solución de controversias. Veamos algunos ejemplos: 
10) El Centro de Arbitraje y Mediación de la Organización Mundial de la Propiedad Intelectual (en adelante, OMPI), que actúa como uno de los centros proveedores del servicio de solución de controversias en materia de registro abusivo de nombres de dominio aprobado por la Internet Corporation for Assigned Names and Numbers (en adelante, ICANN), tiene en vigor un reglamento adicional que prevé que cualquier presentación de escritos que deba hacerse en el procedimiento, podrá realizarse — sin perjuicio del envío de los textos escritos, si lo impone el Reglamento de la ICANN - «en caso de que ambas partes estén de acuerdo, mediante el sistema de presentación de demandas y administración del procedimiento establecido por el Centro y basado en Internet"

2o) La American Arbitration Association tiene previsto un procedimiento suplementario para el arbitraje en línea, aplicable si las partes lo convienen en el acuerdo de arbitraje o, posteriormente, con el acuerdo del árbitro. Las alegaciones de las partes se dirigen, por vía electrónica, a una web puesta a disposición por la institución administradora del arbitraje (portal del caso), aunque la primera alegación de la parte reclamante deberá ser dirigida al portal de la institución administradora. A ese portal se remitirá también el laudo arbitral. Las audiencias de las partes con el árbitro pueden celebrase mediante videoconferencia, tele conferencia u otros medios.

$\left.3^{\circ}\right)$ El denominado CyberTribunal, puesto en funcionamiento por el Centro de Investigación de Derecho Público de la Facultad de Derecho de la Universidad de Montreal, cuenta con un reglamento de procedimiento caracterizado porque este se desarrolla en línea.

El arbitraje en línea puede encontrar importantes dificultades para su efectividad si resulta necesario instar la ejecución del laudo ante los tribunales; es admisible una impugnación jurisdiccional del laudo por razones de la forma electrónica adoptada para su emisión o de esta misma forma adoptada para el convenio arbitral; o, en fin, porque la escasa seguridad de las comunicaciones electrónicas en el desarrollo del procedimiento permita cuestionar el respeto a los principios básicos de audiencia y contradicción.

B) La incorporación de las nuevas tecnologías de la información y de la comunicación a la forma de los procedimientos judiciales y arbitrales

La incorporación a la forma de los procedimientos judiciales y arbitrales de las nuevas tecnologías de la información y la comunicación se caracte- 
rizará, en definitiva, por una nota de relatividad, y ello en un doble sentido. De un lado, razones muy diversas determinarán que sea más idónea o adecuada la tramitación en forma electrónica de los procesos sobre ciertas clases de litigios. Por otro lado, la ley del procedimiento impondrá las nuevas formas de comunicación en aquellas clases de actos procesales para cuyos fines resulten especialmente apropiadas, con lo que se incrementará la ya existente mezcla de formas en el procedimiento.

a) Procedimiento en línea y tipología de litigios

La tramitación en forma electrónica puede estimarse especialmente idónea para ciertas clases de litigios y por causas muy diversas.

$\left.1^{\circ}\right)$ Actividades procesales cuyo desarrollo no precisa de apreciaciones fácticas y jurídicas complejas por parte del juez o de los auxiliares del tribunal. Supuesto paradigmático es el de un procedimiento monitorio con reclamación de deuda dineraria líquida y sin necesidad de justificación documental de la misma. En el que la serie de actos conducentes al título ejecutivo - requerimiento de pago, que debe ser notificado por los medios legales, y constatación de la falta de pago y de oposición en plazo- pueden realizarse por medios informáticos, a partir de la presentación por el reclamante de los datos necesarios de la deuda y del deudor, incluso en soporte electrónico o con remisión por vía electrónica al tribunal competente.

$2^{\circ}$ ) Los litigios específicamente originados en el seno de relaciones jurídicas establecidas para la utilización de las nuevas tecnologías informáticas y de la comunicación. Sirve de ejemplo, en este caso, la oportunidad de un procedimiento en línea para ciertos litigios originados por la colisión entre el registro de un nombre de dominio y derechos de marca registrados.

3o) Litigios originados en relaciones de comercio electrónico, cuya cuantía, generalmente escasa, desaconsejaría, por los costes, acudir a un proceso o a un arbitraje en forma ordinaria.

$4^{\circ}$ ) Asuntos en los que la tutela judicial pretendida ha de ser prestada con la máxima urgencia, como, por ejemplo, las diversas modalidades de tutela especial de derechos fundamentales conocidas en nuestros ordenamientos (amparo, protección, habeas corpus, habeas data). Efectivamente, en esta línea, el Derecho costarricense conoce, desde octubre de 1989, la admisión legal de los medios telemáticos en materia de amparo y habeas corpus. En el contexto del Derecho argentino se postula un procedimiento "virtual" para el amparo sobre la base de la inmediata aplicación de la Ley No 25.506, sobre firma digital. 
b) El mestizaje de las formas procedimentales

Aunque solo se tuvieran presentes las formas tradicionales, se constata que la caracterización oral o escrita del procedimiento no es una cuestión de exclusividad, sino de combinación y predominio de formas.

En cuanto las nuevas tecnologías de la informática y de las comunicaciones crean la posibilidad de realizar actos procesales en forma distinta a la oralidad y a la escritura, la opción por la aplicación de esa nueva forma no se sustrae a la funcionalidad de la misma respecto del fin del acto - modo más perfecto y económico de alcanzar ese fin-como criterio para imponer, precisamente, la observancia de cierta forma, en este caso de una nueva forma.

De ahí que, probablemente, la perspectiva más realista de evolución de la forma de los procedimientos judiciales y arbitrales, será la de un procedimiento según las formas tradicionales, en el que diversos actos se realizarán con los medios que proveen las nuevas tecnologías. Sin excluir procedimientos desarrollados preponderantemente por comunicación electrónica en la red, en los que no podrá prescindirse absolutamente de la aportación de documentos cuya forma no sea electrónica, ni tampoco del contacto directo del tribunal con personas y cosas.

\section{Los significados de la expresión "comercio electrónico»: forma de los negocios jurídicos de Derecho privado y forma de los actos jurídico-públicos, específicamente procesales}

La expresión "comercio electrónico» tiene una acepción estricta y una acepción amplia. La primera es significativa de las transacciones realizadas electrónicamente en materias mercantiles o, algo más ampliamente, de Derecho privado patrimonial.

En la acepción más amplia quedarían comprendidas todas las comunicaciones e intercambios de datos por vía electrónica dirigidos a producir efectos jurídicos. Representaría una (nueva) forma de manifestación del acto jurídico en sentido amplio, es decir de la expresión de la voluntad y pensamiento humanos, a la que el Derecho vincula efectos jurídicos, precisamente por ser tal expresión. Esos efectos jurídicos pueden producirse tanto en el ámbito jurídico-privado, como en el campo del Derecho público, y, por tanto, especialmente en el Derecho procesal.

Probablemente por un característico signo de nuestros tiempos, la expresión "comercio electrónico", que solo es significante de una parte del 
todo, ha sido encumbrada a la primera línea semántica, de manera que destaca la referencia a la materia mercantil, frente a la problemática genérica de la comunicación electrónica como nueva forma de los actos jurídicos.

No obstante, la simple observación de la realidad, revela que las posibilidades que las nuevas tecnologías abren para la realización de actos jurídicos, tienen dos aspectos. Uno común a todo tipo de actuación jurídica que se lleve a cabo según las nuevas formas. Otros aspectos que son específicos para distintas clases de actos jurídicos que, con independencia de los avances tecnológicos y de los cambios sociales, siguen siendo diferentes unos de otros.

El aspecto común comprende dotar a la realización de los actos de la suficiente seguridad en cuanto a la atribución subjetiva de los mismos (autenticidad subjetiva), en cuanto a su contenido completo y no alterado (autenticidad objetiva) y, según casos, también en cuanto a las circunstancias de tiempo y de lugar de su realización.

Pero, por otra parte, habrá aspectos específicos de los que podemos llamar actos procesales digitales o electrónicos (paralelamente a los orales y escritos) que requerirán de normas que respondan a las peculiaridades de las situaciones jurídicas subjetivas (potestades y funciones públicas; facultades y cargas de las partes) y a los fines que haya establecido el ordenamiento para tales actos.

En términos de Derecho positivo esta diferenciación puede conducir a que:

10) La regulación de la firma digital o electrónica atienda a los aspectos comunes, en general a los sistemas para dar seguridad a las comunicaciones electrónicas.

20) Una regulación específica establezca el modo o los supuestos de aplicación del régimen general de la firma digital o electrónica a los actos jurídico-públicos y específicamente a los actos procesales.

A partir de este planteamiento, las diferentes técnicas legislativas aplicadas en cada ordenamiento conducen a conclusiones de diverso grado de seguridad acerca de si la ordenación que pueda estar vigente sobre la firma digital o electrónica es aplicable a los actos procesales.

En este sentido, la técnica legal más perfecta sobre la regulación del empleo de la forma electrónica en la actividad jurídica es la que reparte esa regulación en varios textos legales.

Uno regula la firma electrónica, sus requisitos y modalidades, y las entidades de prestación de los servicios necesarios para la operatividad del sistema. 
Separadamente, una o varias leyes reforman las normas de Derecho Privado, Público y, especialmente dentro de este, las normas procesales, autorizando la realización de actos en forma electrónica y estableciendo la modalidad de firma electrónica que ha de aplicarse en los diferentes supuestos. De este modo queda fuera de duda que esa forma del acto es idónea para su validez y eficacia.

Pero, aun establecida legalmente con claridad la validez de la forma electrónica para los actos procesales y los requisitos para esa validez - generalmente la aposición de una firma electrónica de determinada clase - no están dadas todas las condiciones para su empleo efectivo.

La posición de una firma electrónica de determinada clase no consiste, simplemente, en que el autor del acto utilice, para denotar que lo asume como propio, un signo diferente a la tradicional firma manuscrita, un signo que él puede crear a voluntad.

En primer término, para que sea materialmente posible la inserción de una firma electrónica y la constatación de la misma se requiere un adecuado equipamiento informático, con los correspondientes dispositivos de creación y de verificación de firma.

En segundo lugar, para que pueda entenderse existente una firma electrónica y sus distintas modalidades es necesario — como se verá algo más ampliamente después-- una estructura organizativa de entidades de certificación, encargadas de asignar los dispositivos de creación de firma, previa comprobación de la identidad y, en su caso, de las facultades del titular, de certificar la firma y de publicitar, en su caso, los certificados, así como de asignar los dispositivos de verificación de firma.

La demanda de estos servicios con el objeto de utilizar la firma electrónica en la realización de actos procesales, suscita una diferente problemática según se trate de los justiciables o de los órganos jurisdiccionales.

Los primeros pueden, en principio, contratar libremente estos servicios, prestados con arreglo a la ley de firma electrónica que esté en vigor, y utilizar la firma asignada para presentar actos a los órganos jurisdiccionales, los cuales, en todo caso, habrían de contar con dispositivos de verificación. No obstante, tampoco carecería de sentido que, para las relaciones con los órganos jurisdiccionales, el ordenamiento impusiera la prestación del servicio de certificación por determinada entidad o por ciertas clases de entidades, que habrían de fijarse mediante un acto o disposición reglamentaria del poder público competente. En todo caso, siempre será procedente que, desde la perspectiva de los órganos jurisdiccionales, $-\mathrm{y}$ no, obviamente, desde la 
de cada uno de ellos, sino desde la institucional del Poder Judicial, expresada en una norma legal o en una reglamentaria dictada por el órgano competente-, la admisión de certificados de firma electrónica se supedite a que cumpla condiciones adicionales necesarias para la comprobación de la observancia de las normas procesales en el acto presentado.

Los jueces y el personal auxiliar que desempeña dentro del tribunal determinadas funciones atribuidas por la ley no pueden, ni siquiera dándose los condicionamientos básicos de técnica informática y de oferta legal de servicios de certificación, mediante una decisión personal, asumir una firma electrónica para el ejercicio de sus potestades y funciones oficiales. Para esto resulta necesaria una asignación de firma por razón del cargo, dado que la misma no conferirá validez y eficacia a un acto de una persona privada, sino al del titular legítimo de un puesto de juez o de secretario judicial en determinado órgano. Esto requiere el ejercicio de competencias del órgano de gobierno y administración del Poder Judicial, normalmente en primer lugar reglamentarias - reguladoras del detalle del procedimiento de asignación de firma-, y en todo caso de gestión de la asignación en concreto. Por lo demás, en el caso de acudirse a la prestación de servicios privados de certificación habrán de habilitarse fondos presupuestarios para financiar el coste de tales servicios.

\section{Las materias litigiosas influidas por las nuevas tecnologías y su incidencia en el proceso (prueba y formas de tutela urgente)}

Las nuevas tecnologías tienen también una incidencia indirecta sobre el proceso.

Dan lugar a nuevas materias litigiosas o introducen nuevos elementos en materias litigiosas tradicionales, cuyo tratamiento jurisdiccional requiere respuestas adecuadas.

\section{Principales tipos de materias litigiosas caracterizadas por la influencia de las nuevas tecnologías}

Sin pretensiones de exhaustividad pueden apuntarse las materias litigiosas en las que de manera más frecuente y destacada inciden las nuevas tecnologías. Cabe registrar una litigiosidad respecto a los derechos de la personalidad, que puede producirse a causa de la lesión de los derechos al honor, la intimidad y la propia imagen por difusión de informaciones en la red. 
En especial las nuevas tecnologías posibilitan nuevas formas de ataque al derecho a la intimidad, debido a que la tecnología informática permite un almacenamiento y tratamiento de datos personales que, por la cantidad de la información y por la capacidad técnica de interrelación, pueden tener gran influencia en la consideración de que sea objeto una persona y en el control de la misma. El uso de Internet posibilita técnicamente la captación de datos personales de los usuarios, abundantes y variados, y, en ocasiones, con desconocimiento de los propios interesados.

Por otra parte, las nuevas tecnologías, en particular su aplicación en la red, han supuesto la creación de un nuevo ámbito de desarrollo de la personalidad, en el que también debe ser respetado el derecho a la libre expresión. Dadas las condiciones técnicas en las que la red se desenvuelve, la misma se ha desarrollado como un ámbito especialmente idóneo para la libertad de expresión y resistente a sus límites, incluso a los que se aplican a su ejercicio en ámbitos tradicionales.

Sin embargo, en cuanto se produzca un movimiento de reflujo de esta libertad en la red, por una inadecuada regulación jurídica de la misma, o por una práctica de los controladores del "código" en el sentido de Schlessig, no hay que dudar en postular las mismas repercusiones jurisdiccionales que corresponden a la tutela de la libertad de expresión en ámbitos tradicionales - acceso a una tutela judicial, además urgente en cuanto sea necesario-.

Las nuevas tecnologías también generan litigiosidad en materia de marcas y otras denominaciones protegidas.

En la misma hay que distinguir, de una parte, la que deriva específicamente de la solicitud y asignación como nombre de dominio de segundo nivel (bajo dominio de primer nivel genérico o de país) de términos iguales o similares a los protegidos como marcas u otras denominaciones a favor de titulares distintos al del nombre de dominio.

De otra parte está la litigiosidad que tiene su origen, genéricamente, en la infracción, a través de la presencia y actuación en la red, de los derechos que confieren la marca, otros signos distintivos y el régimen jurídico de tutela de otras denominaciones, por medio de la inclusión no autorizada de los mismos en un sitio web o en su código subyacente, o como un link o frame del mismo.

Particularmente frecuentes y graves son los litigios en materia de derechos de autor y de derechos afines.

Los litigios por lesión de derechos sobre bienes inmateriales se completan con los que se originan por violación de derechos e intereses prote- 
gidos por la legislación sobre competencia desleal o sobre publicidad, producida por actuaciones en la red.

En fin, encontramos la litigiosidad derivada de la contratación electrónica.

\section{Principales repercusiones en el proceso}

Al examinar las materias litigiosas mencionadas se observa, de manera constante, una repercusión sobre la ordenación de la jurisdicción consistente en la dificultad de hallar un punto de conexión de los asuntos litigiosos con los ámbitos de soberanía estatales. De esto derivan problemas respecto a la atribución de la competencia judicial internacional y, en su momento, respecto al reconocimiento y ejecución de resoluciones judiciales extranjeras.

Esta cuestión merecería, por sí sola, una ponencia y, ciertamente, los temas asignados a esta ponencia no la incluyen. En general, basta con indicar que las materias litigiosas influidas por las nuevas tecnologías requieren un planteamiento cooperativo del régimen de la competencia judicial internacional y del reconocimiento y ejecución de resoluciones de tribunales extranjeros. Mientras se adecua la ordenación de las jurisdicciones estatales, los problemas tienden a superarse por la vía del arbitraje internacional

Una repercusión específicamente derivada de los litigios sobre contratación electrónica es la relativa al valor jurídico, y, particularmente, a la eficacia probatoria de los soportes electrónicos como forma de expresión de la voluntad negocial. Estas son las cuestiones referentes a la prueba que en la ponencia deben ser analizadas especialmente.

En fin, sin duda son características de las relaciones sociales y económicas impregnadas por el uso de las tecnologías informática y de las telecomunicaciones, la rapidez con la que se desarrollan las acciones y conductas y la amplia - y, con frecuencia, descontrolada- difusión de sus resultados. Si las acciones y conductas que se desenvuelven en ese ámbito tienen trascendencia jurídica y si, en un caso concreto, pueden ser consideradas ilícitas, aquellas características se proyectan sobre la lesión de derechos e intereses legítimos, que se produce con una celeridad y una fuerza expansiva tales que pueden prácticamente imposibilitar una tutela jurídica efectiva. Esto es lo que justifica que en la ponencia deban examinarse especialmente las cuestiones sobre la tutela cautelar. 


\section{La eficacia probatoria de los soportes electrónicos}

La fijación y constancia del pensamiento y la voluntad humanas que, por mucho tiempo, ha quedado confiada al papel mediante escritura, pueden hoy conseguirse por incorporación a otro tipo de soportes, cuyo tratamiento ofrece grandes ventajas prácticas en cuanto, por ejemplo, el archivo de la información. Principalmente, en cuanto a la transmisión, que puede realizarse con extraordinaria rapidez entre personas que se hallan geográficamente distantes y que no han tenido contacto personal directo.

No obstante, hay una ventaja práctica que no resulta del simple progreso tecnológico. Es el valor jurídico que deba reconocerse a la voluntad y conocimiento humanos expresados en dichos soportes o instrumentos.

Este valor depende del Derecho. Y este lo reconoce o lo niega en función del cumplimiento de unos requisitos indispensables de seguridad que garanticen:

10) Que la declaración procede de quien afirma haberla emitido.

20) Que el contenido de la declaración no ha sido alterado durante la transmisión.

$3^{\circ}$ ) Que el emisor realmente la remitió y el receptor efectivamente la recibió.

Las normas sobre la eficacia jurídica, especialmente jurídico-probatoria, de los soportes electrónicos tienen la estructura de toda norma: supuesto de hecho y consecuencia jurídica. Pero estos componentes tienen una extraordinaria complejidad. En el texto de la ponencia se analizan con detalle. Ahora expondré una síntesis.

A) Las cuestiones del supuesto de hecho: técnicas de seguridad e intervención de los poderes públicos en la regulación y supervisión de las mismas.

El componente extrajurídico o prejurídico del supuesto de hecho está constituido por las técnicas que, desde un punto de vista científico, son idóneas para conseguir, con el mayor grado de probabilidad, los objetivos de seguridad mencionados.

Las técnicas disponibles —en etapa de investigación o experimentación- para dotar de seguridad a la emisión y transmisión de declaraciones en soporte informático, son variadas y, en cuanto su existencia depen- 
de del progreso tecnológico, se hallan abiertas a evolución y cambio. A título ilustrativo se pueden mencionar algunas.

10) En las técnicas de contraseña, la declaración es considerada como emitida por determinada persona porque el receptor de la declaración puede partir de la base de que solo esa persona conoce el dato de identificación (código secreto, número de identificación personal, frase en clave) que ha utilizado para realizar el acto de que se trate.

20) En la técnica de criptografía simétrica o de clave secreta la seguridad se basa en el cifrado o encriptación de la declaración y en la limitada disponibilidad de las claves de cifrado.

$3^{\circ}$ ) Las técnicas biométricas consisten en el uso de características personales absolutamente identificadoras de quien emite la declaración.

$4^{\circ}$ ) Las técnicas de criptografía asimétrica o de clave pública, que son las más difundidas actualmente, se basan en la existencia de dos claves. Una privada, que sirve para encriptar la declaración y que solo ha de ser conocida o estar disponible por su titular. Una clave pública, accesible en general y especialmente a los interesados en transacciones con los titulares de claves. Ambas claves están matemáticamente relacionadas, pero el computo inverso de la relación no debe ser factible a partir de la clave publica, porque ello afectaría a la esencia de seguridad del sistema.

Esta técnica garantiza que, si la clave pública desencripta correctamente la declaración, la declaración ha sido emitida con el uso de la clave privada del titular de la clave pública, y que el contenido de la declaración no ha sido alterado en la transmisión -o, al menos, que no lo ha sido sin el uso de la clave privada-.

El problema de la autenticidad subjetiva -autor de la declaración lo es el que denota el uso de la clave- - se resuelve, al menos en parte, con la figura de las entidades de certificación, que, al tiempo que se encargan de la difusión de las claves públicas, hacen constar que la persona que aparece identificada como titular de una clave pública es, también, la que tiene asignada la clave par privada (secreta).

Es cierto que la simple calidad científico-técnica de los medios de seguridad de las transacciones electrónicas puede dotarlas, en el plano de los hechos, de un altísimo grado de fiabilidad.

Pero estos medios se aplican a transacciones jurídicas respecto de las cuales siempre puede surgir la litigiosidad. Y uno de los motivos de esta litigiosidad puede ser el real o aparente fallo de la técnica. 
Esto nos lleva a la consideración de los diferentes modos de configuración de los supuestos "de hecho" de las normas sobre la eficacia jurídica, en especial probatoria, de las declaraciones formalizadas en soportes electrónicos.

A las reglas de la técnica se superpone una regla jurídica, destinada a determinar cómo debe un tribunal resolver ciertas cuestiones si el asunto litigioso se refiere a una declaración instrumentada electrónicamente o comunicada telemáticamente. Son relevantes, para establecer la certeza de los hechos, las técnicas de seguridad de los soportes de la declaración o de la transmisión de la misma.

Cuando la norma jurídica penetra en este campo lo hace para discriminar entre las diversas técnicas (disponibles o de previsible disposición), atendiendo a características relevantes de las mismas. Para, después vincular a unas sí y a otras no (con determinadas consecuencias jurídicas), o para anudar a las diversas técnicas con consecuencias jurídicas también distintas.

Con inevitable simplificación, se puede hablar de tres grandes modelos.

a) El supuesto «de hecho» limita la eficacia jurídica al caso de que se haya aplicado una concreta regla técnica de seguridad

La ley solo reconocería eficacia jurídica a la declaración formalizada en soporte electrónico si la misma se hubiera efectuado o transmitido con arreglo a unas especificaciones técnicas de seguridad normalizadas y descritas en la propia ley o por remisión de la ley a unos estándares de normalización. Representa una solución inadecuada para el problema ahora considerado, puesto que inmoviliza el tratamiento jurídico de una realidad técnica en constante evolución.

b) Configuración del supuesto de hecho mediante conceptos jurídicos indeterminados, sin ulterior referencia a medios complementarios idóneos para alcanzar los estándares fijados

Pueden servir como ejemplo de este modo de configurar el supuesto de hecho los artículos $7^{0^{1}}$ y $9^{\circ} .2^{2}$ de la Ley Modelo CNUDMI sobre comercio electrónico.

1 «Cuando la ley requiera la firma de una persona, ese requisito quedará satisfecho en relación con un mensaje de datos: a) Si se utiliza un método para identificar a esa persona y para indicar que esa persona aprueba la información que figura en el mensaje de datos; y b) Si ese método es tan fiable como sea apropiado para los fines para los que se generó o comunicó el mensaje de datos, a la luz de todas las circunstancias del caso, incluido cualquier acuerdo pertinente». 
De la absoluta rigidez del modelo anterior pasamos, ahora, a la necesidad de que el juez examine cada caso singular para verificar si se cumplen los conceptos jurídicos indeterminados establecidos por la norma. Para esta tarea precisará indefectiblemente de una prueba pericial muy compleja.

c) El modelo predominante y sus variantes: establecimiento normativo de estándares de seguridad y estructuras destinadas a garantizarlos

Este modelo, sin duda el que se va implantando en la mayor parte de los ordenamientos - aunque su vigencia concurre con la del modelo anterior-combina:

10) La definición de unos estándares normativos de seguridad de las transacciones electrónicas.

$2^{\circ}$ ) Una estructura que tiene por objeto hacer posible el cumplimiento de los estándares de seguridad y está integrada por entidades técnico-empresariales y por administraciones públicas que, con grados diversos de interacción, concretan niveles de seguridad, con repercusión en la eficacia jurídica que deba ser reconocida al soporte electrónico.

El modelo se concreta en los regímenes legales de la firma electrónica, que distinguen - para la posterior asignación de eficacia jurídica, específicamente probatoria- diferentes modalidades de soporte electrónico en función de las técnicas de seguridad de las que se hallan dotados.

Entiendo que, sustancialmente, pueden distinguirse tres modalidades:

1a) Firma electrónica que permite identificar al signatario, cuya creación se halla bajo el exclusivo control del mismo, está amparada por una entidad certificadora - que garantiza la relación entre las claves pública y privada y de éstas con un determinado titular-y que es creada mediante un dispositivo seguro - que dificulta el descubrimiento de la clave secreta, no altera el documento encriptado y puede ser controlado exclusivamente por el titular de la firma-.

En esta modalidad no es necesario que las entidades de certificación y los dispositivos de creación de firma sean previamente controlados por la Administración pública - en cuanto al cumplimiento de los requisitos

2 «'Toda información presentada en forma de mensaje de datos gozará de la debida fuerza probatoria. Al valorar la fuerza probatoria de un mensaje de datos se habrá de tener presente la frabilidad de la forma en la que se haya generado, archivado o comunicado el mensaje, la frabilidad de la forma en la que se haya conservado la integridad de la información, la forma en la que se identifique a su iniciador y cualquier otro factor pertinente». 
que garantizan el alcance de los objetivos de seguridad normativamente fijados- - a los efectos de una autorización u homologación.

$2^{\text {a) }}$ Firma electrónica a la que faltan todas o alguna de las características de la primera modalidad, aunque posibilita técnicamente identificar, en alguna medida, la procedencia del mensaje electrónico.

3a) Firma electrónica con las características de la primera modalidad, con el complemento de que la entidad de certificación y el dispositivo de creación de firma han sido acreditados por la administración pública, previa evaluación del cumplimiento de los requisitos.

B) Las cuestiones referidas a las consecuencias jurídicas: eficacia probatoria de los soportes electrónicos

Corresponde ahora tratar de las consecuencias jurídicas que el ordenamiento vincula a los soportes electrónicos previstos en los supuestos de hecho normativos y además, según hemos visto, con variedad de modalidades.

En primer término, estas consecuencias jurídicas se proyectan sobre el requisito de forma de los actos y negocios jurídicos. Las normas que regulan las consecuencias analizadas autorizan o prohiben, en general o para supuestos específicos, el uso de la forma electrónica, con incidencia sobre la validez o eficacia del acto. Pero de esta materia no ha de tratarse ahora, porque su aspecto procesal fue precisamente considerado en la parte II de la ponencia - la autorización de la forma electrónica para los actos procesales - y en lo demás es una cuestión de Derecho material, referida al requisito de forma de los actos administrativos y de los negocios jurídicos privados.

Nos interesan, ahora, las consecuencias jurídicas en cuanto a la eficacia probatoria, que comprenden desde la admisión de tales soportes como medio de prueba y la clase de medio que es cauce para su introducción, hasta el valor probatorio que se les atribuya.

a) Eficacia probatoria entendida como admisibilidad en cuanto medio de prueba

Tener eficacia probatoria significa, en primer lugar, que las fuentes de prueba en las que consisten los soportes electrónicos, en cuanto soportes materiales y técnicos aptos para generar convicción, son admisibles en un proceso en calidad de medios de prueba. La respuesta dependerá del régimen de la admisión de pruebas de cada ordenamiento, en especial del 
numerus apertus o clausus de medios de prueba, $y$, en el segundo caso, de la previsión legal de un medio adecuado o de la amplitud interpretativa y de integración normativa que permita encuadrar esta nueva fuente, generada por el avance tecnológico, en algún medio expresamente regulado.

Esa respuesta es, de manera general, afirmativa.

b) ¿A través de qué medio de prueba desarrollan su eficacia probatoria los soportes informáticos?

Si es admisible como medio de prueba, ¿cuál es el medio?. Es decir, cuáles son las posibilidades, cargas y deberes procesales de las partes en el caso de que se aporten como prueba, cuáles los poderes del tribunal y cuál la actividad procesal adecuada.

En teoría las posibilidades son dos. El ordenamiento puede regular un medio de prueba específico - así lo ha hecho la nueva LEC española-o puede encuadrar su introducción, con algún ajuste, en alguno o algunos de los medios tradicionalmente previstos - generalmente en la prueba documental, aunque también en un específico régimen del reconocimiento judicial-.

La apreciación crítica de las diferentes soluciones legislativas conduce a estas observaciones:

$\left.1^{a}\right)$ La no asimilación a la prueba documental ha sido criticada porque conduce a excluir la imposición a la parte a quien se opone el contenido del soporte electrónico de cargas como la de manifestarse sobre su autenticidad, a riesgo de que ésta deba ser tenida por cierta. Esta exclusión significa desconocer la identidad funcional con el documento, e incluso la tendencia real a sustituirlo en el tráfico jurídico.

Como réplica habría que apuntar que estos defectos no son consecuencia necesaria de la falta de asimilación a la prueba documental, sino de la falta de previsión, dentro del régimen del medio de prueba específico, de la carga mencionada.

$2^{\text {a) }}$ A diferencia de lo que ocurre con los documentos en sentido estricto, no es generalizable a los soportes electrónicos la carga de acompañamiento de copias con la demanda y la contestación, para que la contraparte las examine y para que asuma, en la primera oportunidad, la carga de impugnar la autenticidad. La laguna puede integrarse por analogía, pero el problema puede surgir en caso de falta de disponibilidad, por la parte que recibe las copias, de instrumentos para la lectura de todo tipo de soportes.

3a) Es necesaria una regulación que posibilite la aportación del soporte si está en poder de la parte que no propone la prueba, o de un tercero. La 
asimilación a la prueba documental resuelve, sin más, el problema si el deber de exhibición de documentos está regulado. La regulación como medio diferenciado no impide, sin embargo, una adecuada solución, bien sea porque puede preverse legalmente el deber de exhibición de los soportes electrónicos, bien porque la laguna puede ser integrada por analogía.

4a) En todo caso, la apreciación por el tribunal del valor probatorio cualquiera sea el modo, legal o libre, de fijar ese valor- requiere tanto unas operaciones técnicas para que el juez tome conocimiento del contenido del soporte, como la práctica de pruebas auxiliares para acreditar y, en su caso, contrarrestar la acreditación- de los diversos elementos que integran las diferentes modalidades de firma electrónica.

c) Eficacia probatoria entendida como valor probatorio: valoración según reglas de la sana crítica, prueba legal y otras técnicas de facilitación del resultado probatorio

Eficacia probatoria significa también, por fin, valor probatorio del medio de prueba practicado, en el sentido de eficacia del mismo para dejar establecido en la sentencia el dato - generalmente de hecho-que constituyó objeto de ese medio de prueba, bien sea por convicción del tribunal, bien porque se den las condiciones para que este aplique una norma vigente de prueba legal.

La eficacia probatoria en este sentido depende del régimen de la valoración de la prueba en cada ordenamiento y dentro de él - porque no suele ser uniforme - del previsto para el medio de prueba (específico o más genérico) en el que se encuadre la introducción en el proceso de los soportes electrónicos.

No obstante, más allá de la dicotomía valoración según sana crítica o valoración legal, el ordenamiento puede haber favorecido ciertas modalidades de soporte electrónico con normas de facilitación de prueba, como presunciones iuris tantum y otras técnicas de finalidad similar.

La calidad de la firma electrónica, según las modalidades antes descritas, condiciona, en los diversos ordenamientos:

10) La atribución del valor probatorio legal que les corresponda por equiparación con los documentos privados y públicos.

20) El sometimiento a valoración libre, en caso de firma electrónica de calidad inferior.

$3^{\circ}$ ) La aplicación de presunciones iuris tantum o de otras reglas de facilitación probatoria. 
Consiguientemente, los diversos elementos fácticos y técnicos que integran las diferentes modalidades de firma electrónica habrán de ser probados para que el tribunal pueda aplicar uno o de otro régimen de valoración probatoria respecto al contenido del soporte o para que, en su caso, aplique las normas de facilitación probatoria.

Se trata de una prueba auxiliar, es decir, de una prueba cuyo objeto son los elementos condicionantes de la frabilidad de otro medio de prueba. Generalmente la prueba auxiliar es necesaria solo eventualmente, en caso de impugnación de la fiabilidad, por ejemplo, del testigo o del documento. Ahora bien, en el medio de prueba de soportes electrónicos (o de documentos electrónicos), si se revisan los modos de configuración de los supuestos de hecho que dan lugar a las diferentes modalidades de los mismos, una prueba auxiliar deberá acompañar siempre a la proposición de la prueba principal.

Sin embargo, puede ser muy diferente el grado de dificultad de la prueba auxiliar para obtener el resultado que persigue la parte que ha propuesto como prueba el soporte electrónico.

Por regla general, será necesaria una prueba documental y pericial con el objeto de probar, por ejemplo, que concurren los requisitos de la firma electrónica avanzada. Es decir, que hay un certificado expedido por entidad facultada legalmente, que la firma ha sido creada por dispositivos controlables exclusivamente por el firmante, que es únicamente atribuible a él y posibilita su identificación, y, en fin, que permite detectar si ha habido alteraciones en el documento.

Pero el ordenamiento puede facilitar la asunción de esta carga probatoria -ciertamente importante y difícil de levantar- si atribuye determinados efectos jurídicos a la acreditación por una administración pública tanto de la entidad certificadora, como de los dispositivos de creación de la firma.

Se ha advertido por la doctrina alemana que la especial norma de prueba prima facie —que la nueva redacción del $\$ 292$ a ZPO vincula a la firma electrónica avanzada cualificada - es de utilidad muy discutible en el caso de que la parte que proponga la prueba tenga que empezar por probar los seis requisitos de esta modalidad de firma. En cambio, adquiere verdadera utilidad si existe previa acreditación administrativa, porque en tal caso rige una presunción técnico-administrativa de seguridad.

De manera, a mi juicio, más contundente, el Art. $3^{\circ} .1$, párrafo segundo del Real Decreto-Ley español dispone que «Se presumirá que la firma 
electrónica avanzada reúne las condiciones necesarias para producir los efectos indicados en este apartado, cuando el certificado reconocido en que se base haya sido expedido por un prestador de servicios de certificación acreditado y el dispositivo seguro de creación de firma con el que ésta se produzca se encuentre certificado [...]».

En definitiva, disposiciones de esta naturaleza posibilitan sustanciar la necesaria prueba auxiliar con la aportación de los documentos públicos que acrediten a la entidad de certificación y el dispositivo de creación de firma utilizado.

4. Las respuestas a la difusión de los efectos de las conductas jurídicamente lesivas en la litigiosidad de las nuevas tecnologías: medidas cautelares y otras formas de tutela provisional

Ya apunté que la litigiosidad influida por las nuevas tecnologías se caracteriza porque los efectos de las conductas lesivas se difunden con celeridad, con gran amplitud y de forma descontrolada.

Esto plantea un nuevo reto a la efectividad de la tutela jurídica, al que los ordenamientos han respondido de maneras muy diferentes, que incluyen la tutela cautelar, pero que no se limitan a la misma.

Veamos las principales respuestas y algunos de sus problemas.

A) Desjudicialización de la tutela jurídica y atribución de potestades a las administraciones públicas.

Las administraciones públicas suelen reunir competencias de control general (reglamentación, registro y supervisión) de un cierto sector o actividad (por ejemplo, empresas dedicadas a servicios de comercio electrónico; actividades de obtención y tratamiento de datos de carácter personal) y competencias de decisión sobre casos singulares de infracción de las normas reguladoras (con potestades de suspensión de actividades, de clausura de establecimientos e instalaciones y de imposición de sanciones pecuniarias elevadas), de modo que, al tratarse de fenómenos sociales que se desarrollan de un modo masivo y temporalmente continuado, la respuesta resulta más adecuada que la actuación caso por caso que puede realizar un órgano jurisdiccional.

Este modelo de actuación de la tutela jurídica — que puede llevar a atribuir a la administración una potestad de previa resolución, incluso 
cuando solo están enfrentados intereses privados - representa una tendencia al cambio de la concepción de la potestad jurisdiccional. Esta deja de ser estrictamente una potestad de actuación del Derecho respecto a relaciones entre personas ajenas al tribunal, para convertirse, progresivamente, en una potestad de control de precedentes resoluciones de órganos no jurisdiccionales, sino administrativos, cualquiera sea el grado de independencia del que estos últimos estén dotados en algunos supuestos. Según cuales sean los condicionamientos constitucionales de cada ordenamiento, puede generar diversos problemas de constitucionalidad.

B) El llamado "procedimiento administrativo» de la ICANN y su aplicación por algunas entidades administradoras de los dominios de nivel superior geográfico

Un medio de tutela de difícil calificación es el denominado procedimiento administrativo adoptado por la ICANN, por recomendación de la OMPI, para la solución rápida y provisional de controversias originadas por el registro de nombres de dominio de nivel superior genérico (sobre todo los .com, .org y .net). Por similitud, pueden lesionar derechos de marca registrados de un tercero, concurriendo además circunstancias reveladoras de especial mala fe en el titular del registro del nombre de dominio. El procedimiento ha sido también adoptado por algunas entidades administradoras de nombres de dominio de nivel superior geográfico o de país.

A pesar de su denominación, no es un procedimiento administrativo, porque la ICANN no es una administración pública. Tampoco es un medio arbitral, porque no tiene el efecto de excluir el acceso a los tribunales.

Veamos sus principales características.

$\left.1^{a}\right)$ Es obligatorio en cuanto constituye una condición general de contratación que se impone al contratar el registro del nombre de dominio.

$2^{\text {a) }}$ Tiende a garantizar la imparcialidad e independencia del encargado de decidir la controversia. Este es un tercero que no forma parte de la entidad competente para el régimen del registro, sino que es designado por la entidad acreditada para administrar el servicio de solución de controversias seleccionada por el demandante.

$3^{\text {a) }}$ Es un procedimiento especial, en cuanto no es adecuado para examinar cualquier reclamación referida al registro de un determinado nombre de dominio, sino solo de las que se fundan en supuestos tipificados de registro abusivo. 
40) El procedimiento es técnicamente sumario, por lo que se acaba de decir y porque su objeto se limita a la cancelación del registro o a la transferencia forzosa del mismo al demandante, sin que se pueda resolver sobre indemnización de daños.

5a) El procedimiento es efectivo, por su breve duración, y, principalmente, porque el cumplimiento de la resolución que se dicte está asegurado mediante el compromiso de cumplimiento por parte de la ICANN y de las entidades de registro acreditadas, lo que evita problemas de ejecución forzosa.

\section{C) Modalidades adecuadas de tutela judicial}

Las materias litigiosas influidas por las nuevas tecnologías requieren una clase de tutela judicial provisional con eficacia para paralizar las conductas que aparezcan como probablemente ilícitas, porque, si se tolera que tales conductas continúen desarrollándose y se confía la reparación a las actuaciones de ejecución forzosa, la tutela judicial puede ser inefectiva por diversas razones:

1a) En unos casos, la naturaleza intrínseca del derecho lesionado — por ejemplo, derechos de la personalidad - determina que el tratamiento indemnizatorio no sea adecuado, sin perjuicio de haber de recurrir al mismo como última ratio.

2a) Cuando el tratamiento indemnizatorio es adecuado o, de cualquier modo, se recurre al mismo, la amplia y descontrolada difusión de las consecuencias dañosas de la conducta ilícita impide, o dificulta esencialmente, que pueda hacerse un cálculo suficientemente fundado y ajustado de las indemnizaciones.

3a) La inexistencia de fronteras para las actuaciones que se llevan a cabo en la red conduce fácilmente a que los daños se produzcan en los ámbitos de diversas soberanías. La obtención a posteriori de una plena indemnidad puede hacer inevitable que la demanda deba presentarse en un foro indeseable para el actor - por ejemplo, ante los tribunales del domicilio del demandado - o incluso en varios foros, para reclamar los daños causados en cada uno de ellos.

4a) En fin, la magnitud del daño puede ser de tal entidad que, aun presuponiendo que pueda ser evaluado y que el perjudicado esté dispuesto a asumir las dificultades - por el foro o foros competentes- en la petición de tutela judicial, el patrimonio del eventual responsable será 
frecuentemente insuficiente incluso para hacer posible una tutela meramente indemnizatoria.

Atendidas estas características de las situaciones litigiosas que justifican la previsión de una tutela judicial urgente, resulta evidente que ésta no puede consistir solamente en medidas cautelares cuyos efectos se hallen limitados al aseguramiento de la ejecución. Medidas de seguimiento y control de la difusión de los resultados de las actividades ilícitas para, en el momento de la ejecución, cuantificar los daños y perjuicios con mayor precisión, medidas de intervención de ingresos obtenidos de tales actividades; o, en fin, medidas de embargo preventivo para asegurar la ejecución de una condena a indemnización, demuestran su ineficacia al chocar con una o con varias de las características que se acaban de reseñar.

La tutela urgente adecuada es aquella cuya eficacia alcance a impedir la incoación de la conducta ilícita - si hay indicios que permiten preverlay, en todo caso, la continuación de la misma.

Los ordenamientos pueden configurar esta clase de tutela de dos modos diferentes:

$\left.1^{\circ}\right)$ Como una tutela sumaria autónoma, que se insta y resuelve en un procedimiento de tramitación rápida, cuyo objeto litigioso puede ser nuevamente planteado en un proceso plenario. Esta es la solución que ofrece el Derecho chileno con el recurso de protección.

$\left.2^{\circ}\right)$ Como tutela cautelar, vinculada y dependiente de un proceso principal, pero con una adecuada amplitud de efectos en cuanto a las medidas que pueden ser adoptadas. Que deben alcanzar, como mínimo, a impedir que, durante el curso de proceso en el que se ha de decidir sobre la conformidad o no a Derecho de la conducta que ha originado el litigio, esa conducta pueda continuar desarrollándose.

Esta es la solución más ampliamente acogida en los ordenamientos de nuestro ámbito.

Respecto de la ordenación de la tutela cautelar en estas materias se plantean algunos problemas específicos de efectividad.

En cuanto al presupuesto de periculum in mora, si el ordenamiento requiere no solo alegar una simple posibilidad de este peligro, sino una probabilidad del mismo en el caso concreto. Habrá que tener presente que, en las materias litigiosas influidas por las nuevas tecnologías, el tránsito de una simple posibilidad de daño a un estado de daño irreversible se produce con extrema celeridad, por lo que no sería adecuado que los tribunales requirieran una acreditación muy rigurosa de este presupuesto. 
La comunicación a través de la red implica la presencia y actividad de múltiples agentes con funciones muy distintas (operadores de telecomunicaciones, proveedores de acceso a Internet, de servicios de alojamiento y transmisión de datos, suministradores de contenidos, etc.). En el plano jurídico-material es una cuestión básica definir la responsabilidad de estos agentes, particularmente de los que prestan servicios de intermediación, a los que solo en supuestos específicos pueden alcanzar las responsabilidades por los contenidos encauzados a través de sus servicios.

Las pretensiones de tutela judicial, incluida la provisional y la cautelar, basta que sean dirigidas frente a quien deba ser considerado responsable, para que la resolución judicial sobre la tutela sea válida desde la perspectiva esencial del principio de contradicción.

Ahora bien, la efectividad de la tutela decretada precisa que las entidades titulares de servicios de intermediación puedan ser requeridas para el cumplimiento de la resolución y deban prestar su colaboración a ese efecto.

Esta materia debe ser objeto de expresa regulación para evitar que la ausencia de responsabilidad oculte la precisa atribución de un deber de colaboración en el cumplimiento de resoluciones judiciales, que no deriva de la posición del prestador del servicio en la relación jurídica material con los usuarios, sino que tiene naturaleza jurídico-pública.

Un último problema es el de las resoluciones cautelares cuya efectividad requiere actuaciones ejecutivas en Estados distintos a aquel cuyos tribunales han dictado la resolución.

El exequátur de resoluciones cautelares es más difícil de obtener que el de sentencias, y, además, aunque sea admitido, conlleva, por las propias características del procedimiento de exequátur, alguna frustración de la efectividad de la medida decretada.

Una alternativa idónea para lo anterior es que la propia medida cautelar pueda ser solicitada de los tribunales del Estado en el que tendrá que ejecutarse, aunque el proceso principal no deba iniciarse después, ni se halle ya pendiente ante los tribunales de ese Estado, por corresponder a otro la competencia judicial internacional para el proceso principal. 